\title{
Toll-like receptor 2 downregulation and cytokine dysregulation predict mortality in patients with Staphylococcus aureus bacteremia
}

Nak-Hyun Kim ${ }^{1,2+}$, Ji Yeon Sung ${ }^{3,4 \dagger}$, Yoon Jung Choi ${ }^{2}$, Su-Jin Choi ${ }^{1}$, Soyeon Ahn ${ }^{5}$, Eunjeong Ji ${ }^{5}$, Moonsuk Kim², Chung Jong Kim ${ }^{2,6}$, Kyoung-Ho Song ${ }^{2}$, Pyoeng Gyun Choe', Wan Beom Park', Eu Suk Kim², Kyoung Un Park ${ }^{3}$, Nam-Joong Kim ${ }^{1}$, Myoung-don $\mathrm{Oh}^{1}$ and Hong Bin $\mathrm{Kim}^{2 *}$ (D)

\begin{abstract}
Background: Staphylococcus aureus bacteremia (SAB) presents heterogeneously, owing to the differences in underlying host conditions and immune responses. Although Toll-like receptor 2 (TLR2) is important in recognizing S. aureus, its function during S. aureus infection remains controversial. We aimed to examine the association of TLR2 expression and associated cytokine responses with clinical SAB outcomes.

Methods: Patients from a prospective SAB cohort at two tertiary-care medical centers were enrolled. Blood was sampled at several timepoints ( $\leq 5 \mathrm{~d}, 6-9 \mathrm{~d}, 10-13 \mathrm{~d}, 14-19 \mathrm{~d}$, and $\geq 20 \mathrm{~d}$ ) after SAB onset. TLR2 mRNA levels were determined via real-time PCR and serum tumor necrosis factor [TNF]-a, interleukin [IL]-6, and IL-10 levels were analyzed with multiplex-high-sensitivity electrochemiluminescent ELISA.

Results: TLR2 levels varied among 59 SAB patients. On days 2-5, TLR2 levels were significantly higher in SAB survivors than in healthy controls $(p=0.040)$ and slightly but not significantly higher than non-survivors $(p=0.120)$, and SAB patients dying within $7 \mathrm{~d}$ had lower TLR2 levels than survivors $(P=0.077)$ although statistically insignificant. IL-6 and IL-10 levels were significantly higher in non-survivors than in survivors on days $2-5$ post-bacteremia $(P=$ 0.010 and $P=0.021$, respectively), and those dying within $7 \mathrm{~d}$ of SAB $(n=3)$ displayed significantly higher IL-10/TNFa ratios than the survivors did $(P=0.007)$.
\end{abstract}

Conclusion: TLR2 downregulation and IL-6 and IL-10 concentrations suggestive of immune dysregulation during early bacteremia may be associated with mortality from SAB. TLR2 expression levels and associated cytokine reactions during early-phase $S A B$ may be potential prognostic factors in $S A B$, although larger studies are warranted.

Keywords: Staphylococcus aureus, Bacteremia, Toll-like receptor 2 (TLR2), Cytokines

\footnotetext{
* Correspondence: hbkimmd@snu.ac.kr

${ }^{\dagger}$ Nak-Hyun Kim and Ji Yeon Sung contributed equally to this work. ${ }^{2}$ Department of Internal Medicine, Seoul National University Bundang Hospital, Seoul National University College of Medicine, 173 Gumi-ro, Bundang-gu, Seongnam 463-707, Republic of Korea

Full list of author information is available at the end of the article
}

(c) The Author(s). 2020 Open Access This article is licensed under a Creative Commons Attribution 4.0 International License, which permits use, sharing, adaptation, distribution and reproduction in any medium or format, as long as you give appropriate credit to the original author(s) and the source, provide a link to the Creative Commons licence, and indicate if changes were made. The images or other third party material in this article are included in the article's Creative Commons licence, unless indicated otherwise in a credit line to the material. If material is not included in the article's Creative Commons licence and your intended use is not permitted by statutory regulation or exceeds the permitted use, you will need to obtain permission directly from the copyright holder. To view a copy of this licence, visit http://creativecommons.org/licenses/by/4.0/. The Creative Commons Public Domain Dedication waiver (http://creativecommons.org/publicdomain/zero/1.0/) applies to the data made available in this article, unless otherwise stated in a credit line to the data. 


\section{Background}

Staphylococcus aureus is an opportunistic pathogen causing various pathological conditions, ranging from asymptomatic colonization to virulent invasive infections including bacteremia [1]. The clinical presentation of $S$. aureus bacteremia (SAB) is heterogeneous; while many patients experience only uncomplicated bacteremia, others exhibit metastatic infections in various organ systems that warrant prolonged antibiotic therapy and often lead to a poor prognosis due to serious sequelae [2]. Many risk factors affecting prognosis in SAB have been identified; host factors include old age [3, 4], presence of comorbidities [5], source of infection and severity of infection at time of presentation [6], and underlying immune status [7, 8], while pathogen-specific factors include methicillin- resistance [9], exotoxins produced by $S$. aureus, and specific $S$. aureus strains $[10,11]$. Other than virulence factors and antibiotic susceptibility of the infecting $S$. aureus, underlying host conditions, and host immune responses contribute to case-by-case variation in host-pathogen relationships, thus resulting in clinical heterogeneity [12-14]. Nevertheless, complex mechanisms underlying the host responses remain unclear.

Upon bloodstream invasion, S. aureus is initially recognized and cleared from circulation by the innate immune system, which is initiated through a sequence of events resulting in the production and secretion of various inflammatory cytokines and chemokines, phagocyte activation, and the initiation of adaptive immunity [14]. Toll-like receptors (TLRs), which are pattern recognition receptors (PRRs) on phagocytic cell membranes, play a pivotal role in recognizing pathogen-associated molecular patterns on bacterial cell walls and activating intracellular signaling pathways [15]. In particular, TLR2 has been reported to be involved in the recognition of staphylococcal peptidoglycan, lipoteichoic acid, and lipoproteins $[14,16,17]$. Upon activation, TLR2 triggers inflammatory signaling pathways, resulting in increased expression and secretion of various antimicrobial peptides, cytokines, and chemokines, which recruit immune cells to the site of infection and trigger the adaptive immune response [17-19]. Notably, S. aureus produces staphylococcal superantigen-like protein 3 (SSL3) and TIR-containing protein (TirS) during infections, which interfere with TLR2 signaling and dampen appropriate TLR2 activation [20-23].

Although TLR2-mediated immune responses during staphylococcal infections have been extensively studied, most evidence has been obtained from in vitro studies or in vivo murine models, with varying outcomes [17, 21]. While immune responses primarily triggered through TLR2 signaling are pro-inflammatory, immunoregulatory responses mediated by TLR2 have also been reported [16, 24]. Some human studies on TLR2 expression in sepsis patients have reported that TLR2 is upregulated in sepsis patients and down-regulated in severe sepsis and septic shock patients, leading to death [25-27]. However, studies on SAB in humans are scarce $[27,28]$.

Therefore, the aims of this study were to assess TLR2 expression and associated host cytokine responses during the course of $\mathrm{SAB}$, and to examine how they differ on the basis of clinical outcomes of SAB at different stages of the infection.

\section{Methods \\ Patients}

SAB patients older than 18 years were enrolled from a prospective SAB cohort from March 2014 to April 2015 in two tertiary-care hospitals in Korea: Seoul National University Hospital, Seoul and Seoul National University Bundang Hospital, Gyeonggi-do. Cases of suspected contamination and polymicrobial infection were excluded, along with patients with a WBC count less than 4000/ $\mu \mathrm{L}$, and those who declined to participate in the study.

Clinical data including demographic characteristics, Charlson's comorbidity-weighted index (CCWI) score [29], severity of acute infection as measured on the basis of the Pitt bacteremia score [30] and sequential organ failure assessment (SOFA) score [31], nosocomial or community-acquired bacteremia with a history of previous health care contact [32], antimicrobial therapy, inhospital mortality, and methicillin resistance of blood isolates were obtained. Appropriate antimicrobial therapy was grossly defined as treatment with susceptible antibiotics based on antimicrobial susceptibility test (AST) results; for methicillin-resistant $S$. aureus (MRSA), appropriate antimicrobial therapy included glycopeptides (with therapeutic drug monitoring for vancomycin), linezolid, and alternative agents according to AST results when treatment with glycopeptides or linezolid was not feasible, and for methicillin-susceptible $S$. aureus (MSSA), $\beta$-lactams and alternative agents based on AST results, in case of $\beta$-lactam hypersensitivity, were regarded appropriate [2]. SAB-related mortality was defined as death within $30 \mathrm{~d}$ of SAB onset without other apparent causes of death [33]. Persistent bacteremia was defined as the isolation of $S$. aureus from blood cultures on $>4$ consecutive days despite treatment with appropriate antibiotics [34, 35].

\section{Sample collection}

We used timed collected residual peripheral blood samples to analyze TLR2 expression levels and cytokine levels. The samples were obtained at five different timepoints: within $5 \mathrm{~d}$ ( $\leq \mathrm{D} 5), 6-9 \mathrm{~d}$ (D6-9), 10-13 d (D1013), 14-19 d (D14-19), and after $20 \mathrm{~d}(\geq \mathrm{D} 20)$ of 
bacteremia onset. Day 0 was defined as the day of the first $S$. aureus-positive blood culture. Among the individuals discharged (transferred) or those who died within $14 \mathrm{~d}$ of admission, only one or two samples were obtained. If more than one sample was available within one period, average TLR2 expression levels were obtained for the samples in that period. Twenty-five healthy volunteers $[22$ females and 3 males; mean age, 32 years (range 22-46 years)], free of signs of inflammation and underlying diseases, were included in the control group.

\section{Ethical approval}

This study was approved by the Committee of Institutional Ethics Review Board at Seoul National University Hospital (1403-024-562) and Seoul National University Bundang Hospital (B-1402-237-002). All participants, including healthy volunteers, provided written informed consent unless the requirement for informed consent was waived.

\section{Measurement of TLR2 expression}

RNA was extracted from whole blood using QIAamp RNA Blood Mini kit (Qiagen, Valencia, CA, USA) in accordance with the manufacturer's instructions. Extracted RNA was either directly converted to cDNA through RT-PCR or frozen at $-70^{\circ} \mathrm{C}$. RT-PCR was performed using SuperScript III Reverse Transcriptase (Invitrogen, Carlsbad, CA, USA). cDNA was stored at $-70^{\circ} \mathrm{C}$ until amplified through real-time quantitative PCR (qPCR). Real-time qPCR was performed to measure TLR2 expression levels using TaqMan Gene Expression Assays (Life Technologies, Carlsbad, CA, USA) for TLR2 (cat\# 4331182, Hs00610101_m1) and GAPDH (cat\# 4448484, Hs99999905_m1). mRNA levels were quantified using an ABI7500 system (Applied Biosystems, Foster City, CA, USA). TLR2 mRNA expression levels were determined as the ratio of TLR2 mRNA to GAPDH mRNA using the $2^{-\Delta \Delta C t}$ method [36]. Each sample was measured in triplicate and the mean value was used in the calculations. We used the MIQE guideline as a reference [37].

\section{Measurement of cytokine concentrations}

Serum was separated from whole blood and frozen at $-70^{\circ} \mathrm{C}$ for future use. The concentration of three cytokines, tumor necrosis factor-alpha (TNF- $\alpha$ ), interleukin-6 (IL-6), and IL-10 were measured in duplicate, using a V-PLEX customized panel kit (Meso Scale Discovery [MSD], Rockville, MD, USA) in accordance with the manufacturer's protocol. Data were acquired using a SECTOR S 600 plate reader (MSD, Rockville, MD, USA).

\section{Statistical analysis}

Statistical analyses were primarily performed using IBM SPSS statistics (version 22.0 software package; SPSS Inc., Chicago, IL, USA) and plotted using GraphPad Prism (version 6.01; GraphPad Software, San Diego, CA, USA). Linear mixed modelling was conducted using R 2.10 ( $R$ Foundation, Vienna, Austria). Data are presented as mean \pm standard deviation (SD), median \pm interquartile range (IQR), and proportions, depending on data distribution type. To compare baseline demographics and clinical data, $x^{2}$ tests and Fisher's exact tests were performed for categorical variables and independent $t$-tests, and Mann-Whitney U-tests were performed for continuous variables, respectively.

Longitudinal analyses of TLR2 expression and cytokine levels were conducted through linear mixed modelling (LMM), adjusting for sex, age and 30-day mortality, severity of infection, methicillin resistance of $S$. aureus blood isolates, and complicated bacteremia. A two-tailed $p<0.05$ was considered statistically significant.

\section{Results}

\section{Clinical and microbiological characteristics}

Among 281 SAB patients, 109 were considered eligible and 65 patients consented to participate. Real-time PCR results were not obtained for six patients, thus yielding 59 patients for analysis (Fig. 1). Age of patients ranged from 26 to 85 years (mean \pm standard deviation, $60.7 \pm$ $16.3)$ and $78.0 \%(46 / 59)$ were male. MRSA was isolated in $61.0 \%(36 / 59)$. SAB-related mortality was $16.9 \%$

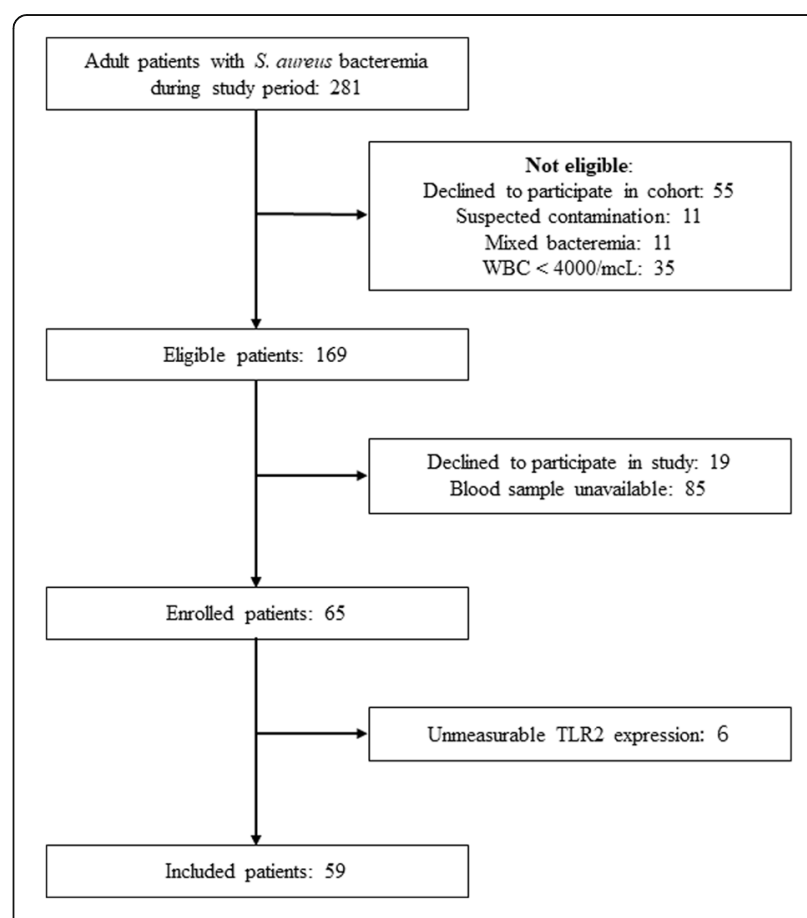

Fig. 1 Schematic representation of the protocol for patient selection 
(10/59), and in-hospital mortality was $18.6 \%$ (11/59). The most frequent primary focus of bacteremia was from a central venous catheter $(25.4 \%, 15 / 59)$. The clinical characteristics of the 59 patients enrolled are summarized in Tables 1 and 2, and a comparison of the clinical characteristics of the enrolled and unenrolled patients in the SAB cohort is summarized in Supplementary Table 1.

Table 1 Clinical characteristics of patients $(n=59)$

\begin{tabular}{|c|c|}
\hline Characteristics & $N(\%)^{a}$ \\
\hline Age (mean [range]) (years) & $60.7[26-85]$ \\
\hline Male & $46(78.0)$ \\
\hline MRSAB & $36(61.0 \%)$ \\
\hline Length of total hospital stay (median [IQR]) (d) & 27.0 [17.0-46.0] \\
\hline Duration of bacteremia (median [IQR]) (d) & $2.0[1.0-4.0]$ \\
\hline \multicolumn{2}{|l|}{ Onset of infection } \\
\hline Community-associated & $11(18.6)$ \\
\hline Community-onset, healthcare-associated & $22(37.3)$ \\
\hline Hospital-onset & $26(44.1)$ \\
\hline In ICU at first positive blood culture & $5(8.5)$ \\
\hline CCWI score (median [IQR]) & $5.0[2.0-7.0]$ \\
\hline Pitt bacteremia score (median [IQR]) & $1.0[0.0-3.0]$ \\
\hline SOFA score (median [IQR]) & $4.0[1.0-8.0]$ \\
\hline \multicolumn{2}{|l|}{ Severity } \\
\hline Non-sepsis & $9(15.3)$ \\
\hline Sepsis & $35(59.3)$ \\
\hline Severe sepsis & $8(13.6)$ \\
\hline Septic shock & $7(11.9)$ \\
\hline \multicolumn{2}{|l|}{ Primary site of infection } \\
\hline Central venous catheter & $15(25.4)$ \\
\hline Bone and joint & $14(23.7)$ \\
\hline Skin and soft tissue & $7(11.9)$ \\
\hline Lower respiratory tract & $6(10.2)$ \\
\hline Cardiovascular site $^{\mathrm{b}}$ & $9(15.3)$ \\
\hline Unknown & $6(10.2)$ \\
\hline Others $^{c}$ & $2(3.4)$ \\
\hline \multicolumn{2}{|l|}{ Treatment } \\
\hline Appropriate empirical & $40(67.8)$ \\
\hline Appropriate definitive $^{d}$ & $59(100)$ \\
\hline Time until appropriate antibiotic (mean \pm SD) (h) & $30.5 \pm 26.3$ \\
\hline SAB-related 30-day mortality & $10(16.9)$ \\
\hline Persistent SAB & $14(23.7 \%)$ \\
\hline Metastatic SAB & $6(10.2)$ \\
\hline
\end{tabular}

${ }^{a}$ unless otherwise specified

b includes infective endocarditis (3) and other endovascular infections (6)

c intraabdominal (1), and urinary tract infection (1)

${ }^{d}$ treatment with susceptible antibiotics

$S D$ standard deviation, MRSAB methicillin-resistant S. aureus bacteremia, IQR interquartile range, CCWI Charlson's comorbidity-weighted index, SOFA sequential organ failure assessment
TLR2 mRNA expression in SAB patients and healthy controls

Patient blood samples were collected at $\leq \mathrm{D} 5$, D6-9, D10-13, D14-19, and $\geq$ D20 (range: D2-48) postbacteremia. Temporal changes in TLR2 mRNA levels varied among patients: TLR2 mRNA was upregulated in some patients and downregulated in others (Supplementary Fig. 1).

Furthermore, during $\leq \mathrm{D} 5$ post-bacteremia, TLR2 mRNA expression levels were significantly higher among SAB survivors than among healthy controls $(p=0.040)$ and slightly but not significantly higher than those among patients who died within $30 \mathrm{~d}$ of onset of bacteremia, with less dynamic changes $(p=0.120)$ (Fig. 2; Supplementary Fig. 2).

Host cytokine concentrations and TLR2 expression in SAB and their association with severity and clinical outcomes Longitudinal analyses by LMM revealed that TNF- $\alpha$, IL6 , and IL-10 concentrations were significantly increased in $\mathrm{SAB}$ patients who died within $30 \mathrm{~d}$ post-bacteremia (with SAB patients who survived as reference) $(p=0.001$, $p=0.002$, and $p<0.001$, respectively). Furthermore, IL-6 and IL-10 levels were significantly increased in patients with septic shock (relative to individuals without sepsis as controls) $(p=0.010$, and $p=0.033$, respectively); IL-6 levels were significantly increased in patients who developed metastatic infections (relative to individuals without metastatic infections as controls $)(p=0.016)$.

When compared within each time period, during $\leq \mathrm{D} 5$ post-bacteremia, IL-6 and IL-10 levels were significantly higher in SAB patients who died within $30 \mathrm{~d}$ (median [IQR], 58.43 [19.12-305.07] vs 11.69 [6.19-21.51] pg/ $\mathrm{mL}, p=0.010$ and $7.15[1.99-15.46]$ vs 2.08 [0.90-3.50] $\mathrm{pg} / \mathrm{mL}, \quad p=0.021$, respectively) than in the SAB survivors. Furthermore, IL-6 and TLR2 levels were significantly higher in patients who developed metastatic infections than in those who did not develop metastatic infections (IL-6: 46.69 [11.24-226.78] vs 11.80 [6.14$24.48] \mathrm{pg} / \mathrm{mL}, p=0.050$; TLR2: 0.63 [0.29-1.29] vs 0.24 [0.13-1.44], $p=0.046)$. Moreover, TNF- $\alpha$ levels were significantly higher in patients with persistent bacteremia than in those with short-term bacteremia (11.51 [4.51$15.65]$ vs 5.46 [3.18-8.91] pg/mL, $p=0.028$ ) (Fig. 3). IL6 and IL-10 levels and the IL-10/TNF- $\alpha$ ratio were higher and TLR2 expression levels were lower in SAB patients who died within $7 \mathrm{~d}(n=3)$ than in SAB survivors (Supplementary Table 2). During D10-13 post-bacteremia, TNF- $\alpha$, IL-10, and IL-6 levels were significantly higher in patients with persistent bacteremia than in patients whose SAB resolved in $4 \mathrm{~d}$ (TNF- $\alpha$ : 10.41 [4.23-17.14] vs 4.36 [3.31-9.39] $\mathrm{pg} / \mathrm{mL}, p=0.038$; IL-10: 2.69 [1.71-4.92] vs 1.18 [0.68-2.10] $\mathrm{pg} / \mathrm{mL}, p=$ 0.038; IL-6: 17.54 [6.58-31.68] vs 6.49 [2.85-12.62] pg/ 
Table 2 Comparison of clinical characteristics of Staphylococcus aureus bacteremia patients based on 30-day mortality

\begin{tabular}{|c|c|c|c|}
\hline Characteristics & Survivors $(n=49)^{a}$ & Non-survivors $(n=10)^{\mathrm{a}}$ & $P$ \\
\hline Age (mean [range]) (years) & $59.4[26-85]$ & $66.8[48-85]$ & 0.166 \\
\hline Male & $38(77.6)$ & $8(80.0)$ & 0.865 \\
\hline MRSAB & $29(59.2 \%)$ & $7(70.0)$ & 0.523 \\
\hline Length of total hospital stay (median [IQR]) (d) & $28.0[20.0-49.0]$ & $14.5[7.5-35.3]$ & 0.022 \\
\hline Duration of bacteremia (median [IQR]) (d) & $1.0[1.0-3.5]$ & $4.5[1.0-5.3]$ & 0.272 \\
\hline Onset of infection & & & 0.592 \\
\hline Community-associated & $10(20.4)$ & $1(10.0)$ & \\
\hline Community-onset, healthcare-associated & $17(34.7)$ & $5(50.0)$ & \\
\hline Hospital-onset & $22(44.9)$ & $4(40.0)$ & \\
\hline Location at the time of first positive blood culture & & & 0.338 \\
\hline General ward & $20(40.8)$ & $4(40.0)$ & \\
\hline ICU & $3(6.1)$ & $2(20.0)$ & \\
\hline Emergency room & $26(53.1)$ & $4(40.0)$ & \\
\hline CCWI score (median [IQR]) & $4.0[1.5-7.0]$ & $6.0[3.0-8.0]$ & 0.174 \\
\hline Pitt bacteremia score (median [IQR]) & $1.0[0.0-2.0]$ & $2.0[1.0-4.0]$ & 0.032 \\
\hline SOFA score (median [IQR]) & $4.0[1.0-7.0]$ & $7.0[5.3-9.8]$ & 0.042 \\
\hline Severity & & & 0.577 \\
\hline Non-sepsis & $7(14.3)$ & $2(20.0)$ & \\
\hline Sepsis & $31(63.3)$ & $4(40.0)$ & \\
\hline Severe sepsis & $6(12.2)$ & $2(20.0)$ & \\
\hline Septic shock & $5(10.2)$ & $2(20.0)$ & \\
\hline Primary site of infection & & & 0.770 \\
\hline Central venous catheter & $12(24.5)$ & $3(30.0)$ & \\
\hline Bone and joint & $13(26.5)$ & $1(10.0)$ & \\
\hline Skin and soft tissue & $5(10.2)$ & $2(20.0)$ & \\
\hline Lower respiratory tract & $4(8.2)$ & $2(20.0)$ & \\
\hline Cardiovascular site $^{\mathrm{b}}$ & $8(16.3)$ & $1(10.0)$ & \\
\hline Unknown & $5(10.2)$ & $1(10.0)$ & \\
\hline Others $^{c}$ & $2(4.1)$ & $0(0.0)$ & \\
\hline \multicolumn{4}{|l|}{ Treatment } \\
\hline Appropriate empirical & $35(71.4)$ & $5(50.0)$ & 0.266 \\
\hline Appropriate definitive ${ }^{d}$ & $49(100)$ & $10(100)$ & \\
\hline \multicolumn{4}{|l|}{ MRSA } \\
\hline Vancomycin (n) & 34 & 7 & \\
\hline Linezolid (n) & 1 & & \\
\hline Fluoroquinolone (n) & 1 & & \\
\hline \multicolumn{4}{|l|}{ MSSA } \\
\hline Nafcillin (n) & 16 & 3 & \\
\hline Cefazolin (n) & 3 & & \\
\hline Ampicillin (n) & 1 & & \\
\hline Time until appropriate antibiotic (mean \pm SD) (h) & $31.0 \pm 28.0$ & $28.0 \pm 16.4$ & 0.911 \\
\hline Persistent SAB & $9(18.4)$ & $5(50.0)$ & 0.047 \\
\hline Metastatic SAB & $4(8.2)$ & $2(20.0)$ & 0.266 \\
\hline
\end{tabular}

${ }^{\mathrm{a} D a t a}$ are given as number (\%), unless otherwise specified

${ }^{\mathrm{b}}$ includes infective endocarditis and other endovascular infections

c surgical wound, and urinary tract infection

${ }^{d}$ treatment with susceptible antibiotics

MRSAB methicillin-resistant S. aureus bacteremia, IQR interquartile range, CCWI Charlson's comorbidity-weighted index, SOFA sequential organ failure assessment MSSA methicillin-susceptible $S$. aureus 


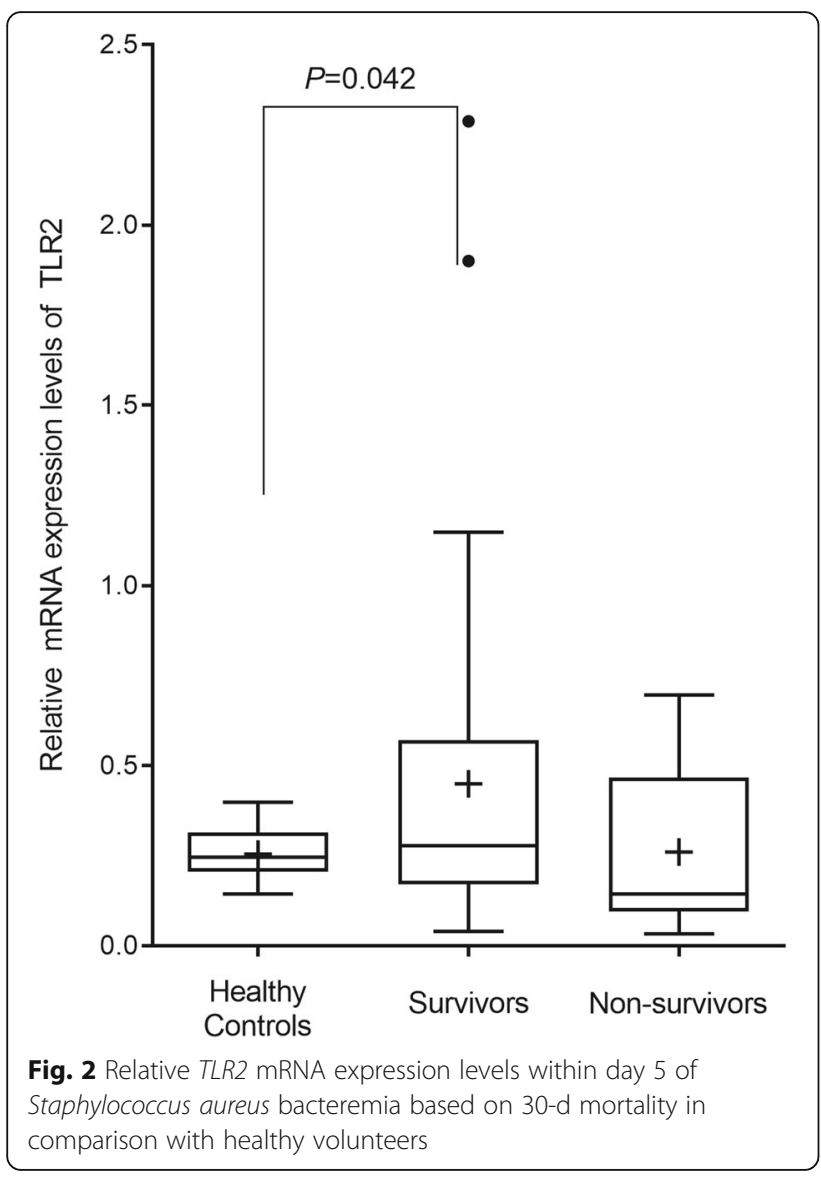

$\mathrm{mL}, p=0.018)$. Cytokine profiles and TLR2 expression levels among the outcome groups did not display significant differences at all other timepoints.

\section{Discussion}

Host immune responses during infection are one of the factors contributing to the clinical outcomes of SAB, and previous studies have reported that the marked heterogeneity in the clinical spectrum of SAB may result from differential inflammatory responses to $S$. aureus $[12,13,34,38]$. TLR2 is reportedly the key sensor of $S$. aureus infections and the primary trigger for innate immune responses [17]. However, available literature contains diverse descriptions of TLR2 function in the immune response to $S$. aureus infections $[16,17,24]$, and evidence from human studies are limited. TLR2 expression and associated cytokine levels were analyzed during the course of $\mathrm{SAB}$ to investigate their associations with $\mathrm{SAB}$ severity and clinical outcomes. The present data show that TLR2 is expressed during early stage SAB, and TLR2 downregulation may be associated with mortality in SAB. Furthermore, the levels of proand anti-inflammatory cytokines were significantly higher in $S A B$ non-survivors than in survivors, suggesting the dysregulation of inflammatory responses.
Previous murine studies have reported that TLR2deficient mice are more susceptible to $S$. aureus infections with a higher bacterial burden and resulted in a higher mortality rate [15]. TLR2 deficiency is suggested to impair phagocytosis, attenuate pro-inflammatory cytokine production, and lead to high mortality [15, 39]. Similarly, in a study on sepsis patients, TLR2 was upregulated in sepsis; however, mortality was associated with TLR2 downregulation [25]. Our results, although not statistically significant, are consistent with these findings, suggesting that TLR2-activity triggered upon bacteremia onset is important for early bacterial clearance and more favorable clinical outcomes of SAB. The lack of statistical significance could be explained by the complex interaction between TLR2 and S. aureus in vivo. First, TLR2-activity seems to be influenced by multiple bacterial factors including proliferative activity, capsule formation, protein synthesis, and cell-wall active factors. Hilmi et al. reported marked variability in TLR activity toward $S$. aureus isolates, displaying low to absent TLR2-activity in $64 \%(68 / 106)$ of the isolates tested [40]. Furthermore, Hanzelmann et al. reported strain-specific TLR2-activity among $S$. aureus isolates, showing that strong TLR2 stimulation depends on an active AGR system and is associated with high level phenol-soluble modulin (PSM) production [41]. Second, the route and site of infection seem to influence TLR2-mediated immune responses, as reported in murine studies using TLR2-deficient mice [21]. Although protective roles of TLR2 signaling have been suggested in models of intravenous infection, localized responses to infections have displayed variable outcomes $[15,21]$. Third, antimicrobial therapy is also likely to affect the expression of PRRs, including TLR2, by various mechanisms. Testro et al. reported that TLR4 expression was upregulated by antibiotic prophylaxis targeting Gram-negative bacteria in patients with liver cirrhosis [42], and Moore et al. showed that beta-lactams enhanced TLR2 activation by inducing structural changes on the surface of pneumococci, whereas vancomycin did not [43]. Using an in vitro sepsis model, Bode et al. examined the immunomodulatory effects of quinolones, tetracyclines, and macrolides and showed that TLR expression on monocytes and peripheral blood mononuclear cells was differently modulated according to antibiotic treatment [44]. Fourth, host responses to $S$. aureus infections are complex and other PRRs, including NOD-like receptors and C-type lectin receptors, are also involved in bacterial recognition and the induction of inflammatory reactions in response to $S$. aureus infections [22]. The complexity of real-life circumstances dampens the significance of TLR2-activity under controlled in vitro conditions.

Both pro- and anti-inflammatory responses occur during $S$. aureus-induced TLR2 activation [15, 16], along 
a
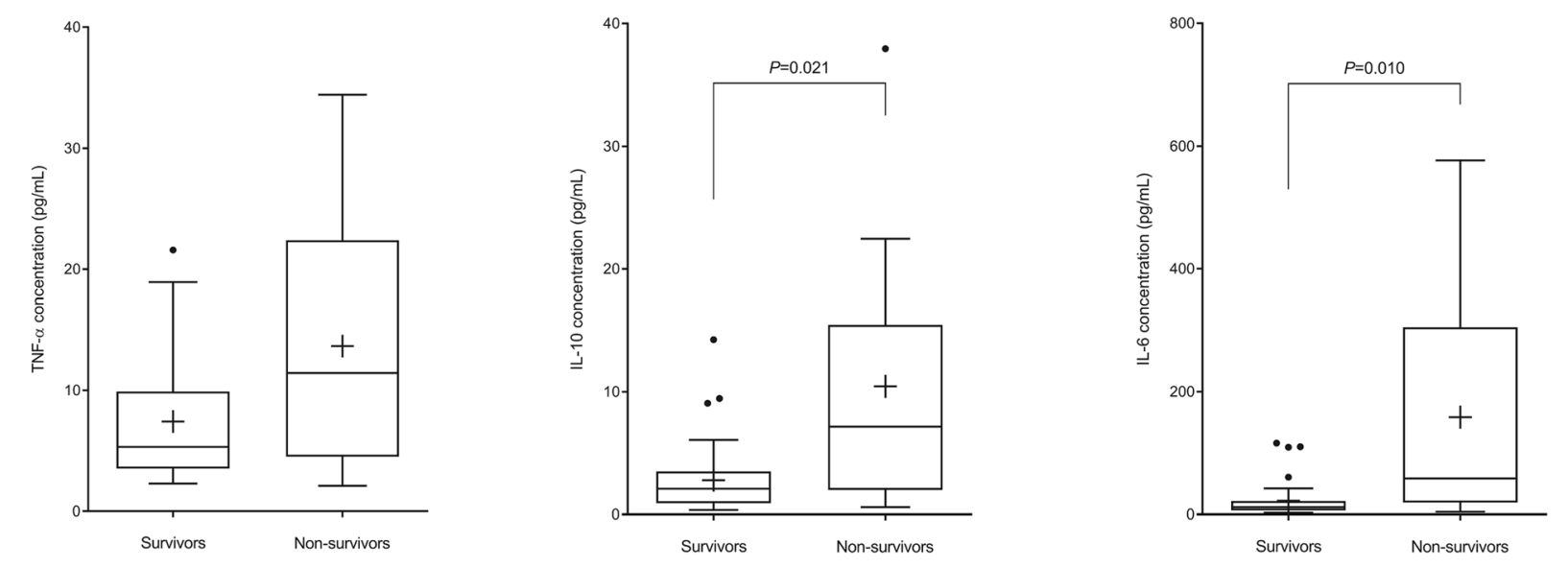

b
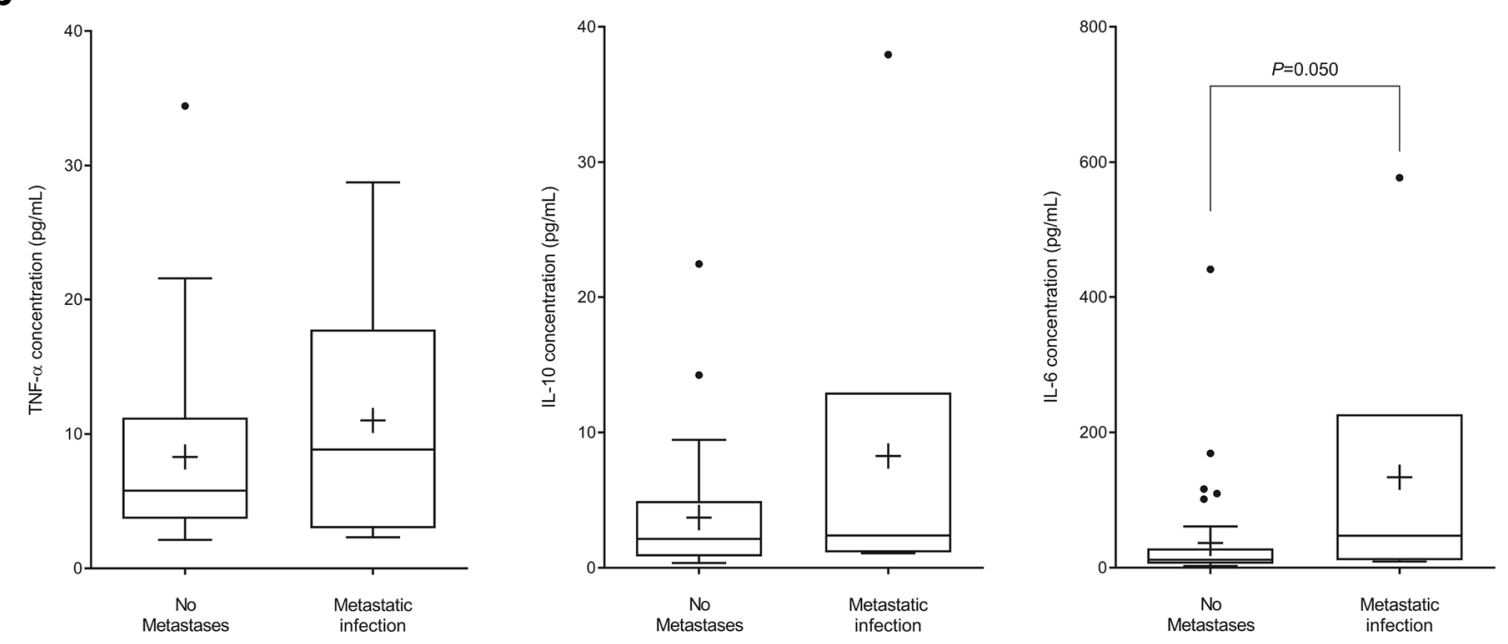

C
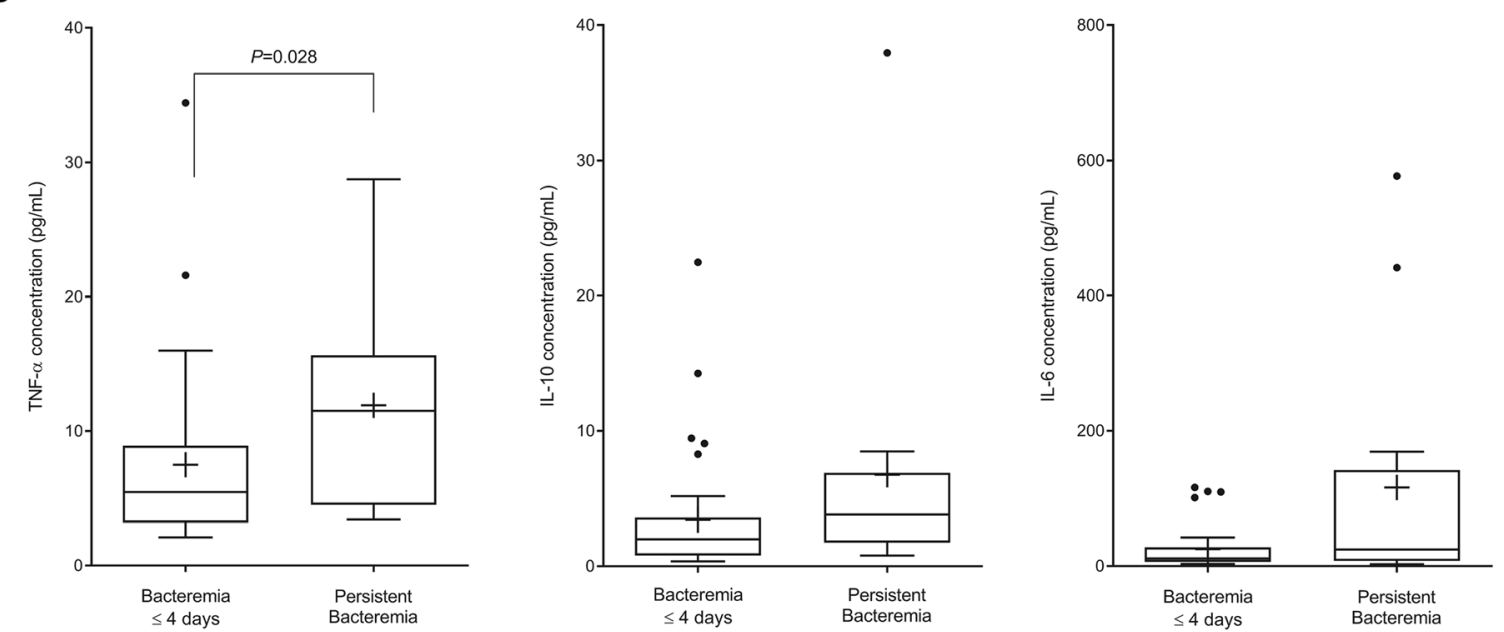

Fig. 3 Cytokine concentrations within day 5 of Staphylococcus aureus bacteremia based on (a) 30-d mortality, (b) development of metastatic infections, and (c) persistence of bacteremia. a 30-day mortality. b development of metastatic infections. c persistence of bacteremia 
with dysregulated cytokine responses, characterized by elevated IL-10 levels and IL-10/TNF ratios, which are considered responsible for the variations in the clinical outcomes of SAB [12, 13, 38]. Previous studies involving sepsis patients have reported that elevated IL-6 levels are associated with sepsis severity and death [45], and McNicholas et al. reported that IL-6 levels are significantly increased in patients with complicated SAB [12]. Elevated IL-10 levels and a high IL-10/TNF- $\alpha$ ratio have been associated with mortality in severe sepsis patients [46], and similar findings have been previously reported among SAB patients [38]. Consistent with the literature, in this study, patients who died from SAB had significantly higher IL-6 and IL-10 levels during early-stage bacteremia, and patients who died within 7 days of SAB onset further displayed a significantly elevated IL-10/ TNF- $\alpha$ ratio and TLR2 downregulation. These results suggest that dysregulated immune responses contribute to SAB-related mortality.

This is the first study to investigate the association among TLR2 expression, cytokine responses, and clinical outcomes in SAB patients. We measured TLR2 expression and cytokine levels throughout the course of $\mathrm{SAB}$ (range D2-48) to examine their association with SAB severity and clinical outcomes. Although a correlation between cytokine levels and TLR2 expression could not be determined, our results indicate TLR2 downregulation and significant immune dysregulation in $\mathrm{SAB}$ patients with early mortality during early-stage SAB. Furthermore, TNF- $\alpha$, IL- 6 , and IL-10 levels were elevated in persistent SAB patients on D10-13.

This study has some limitations, particularly as this study was performed under actual clinical conditions. First, this study was part of a prospective cohort study, not an interventional study; hence, clinical samples could not be obtained at the same time points postbacteremia, i.e., the timing and total numbers of postbacteremia blood samples from each patient was different. Therefore, for statistical analysis, we arbitrarily assigned sampling time points as $\leq \mathrm{D} 5, \mathrm{D} 6-9, \mathrm{D} 10-13$, D14-19 and $\geq$ D20, thus potentially resulting in bias. However, as in most patients, since the first sample was collected at D3-5, we believe that the measurements during early-stage SAB are largely comparable. Second, since we only included patients who consented to participate, clinically unstable patients were less likely to be enrolled, and the number of patients with worse outcomes was relatively small. Although SAB mortality was lower than that reported in previous studies [47], the clinical characteristics of the enrolled patients and the excluded patients did not significantly differ. Third, we did not analyze bacterial factors including the AGR status, toxigenicity, or inoculum doses, which could have influenced the immune responses and clinical outcomes.

\section{Conclusions}

This study indicated that TLR2 downregulation, and IL-6 and IL-10 elevation during early SAB may be associated with mortality from SAB. Furthermore, dysregulated inflammatory responses characterized by elevated IL-10/TNF- $\alpha$ ratios were associated with mortality within $7 \mathrm{~d}$ of SAB onset. Therefore, TLR2 expression levels and associated cytokine reactions during the early-stage may be considered potential prognostic factors in SAB.

\section{Supplementary Information}

The online version contains supplementary material available at https://doi. org/10.1186/s12879-020-05641-z.

Additional file 1: Supplementary Table 1. Comparison of clinical characteristics of enrolled and unenrolled patients with Staphylococcus aureus bacteremia from March 2014 to April 2015. Supplementary Table 2. Relative TLR2 mRNA expression levels and cytokine concentrations within day 5 of Staphylococcus aureus bacteremia (SAB) based on early mortality (mortality within $7 \mathrm{~d}$ of SAB onset).

Supplementary Fig. 1. Relative TLR2 mRNA expression levels relative to those of GAPDH mRNA among all patients. Supplementary Fig. 2. Relative TLR2 mRNA expression levels based on 30-d mortality.

\section{Abbreviations}

SAB: Staphylococcus aureus bacteremia; TLR: Toll-like receptor; PRRs: Pattern recognition receptors; SSL3: Staphylococcal superantigen-like protein 3;

TirS: TIR-containing protein; CCWI: Charlson's comorbidity-weighted index; SOFA: Sequential organ failure assessment; AST: Antimicrobial susceptibility test; MRSA: Methicillin-resistant S. aureus; MSSA: Methicillin-susceptible S. aureus; qPCR: Quantitative PCR; TNF: Tumor necrosis factor; IL: Interleukin; SD: Standard deviation; IQR: Interquartile range; LMM: Linear mixed modelling; PSM: Phenol-soluble modulin

\section{Acknowledgements}

We would like to thank Editage (www.editage.co.kr) for English language editing.

\section{Authors' contributions}

NHK: Conceptualization, Methodology, Data curation, Writing- Original draft preparation, Writing - Review \& Editing. JYS: Conceptualization, Methodology, Investigation, Writing- Original draft preparation. YJC, SJC: Methodology, Investigation. SA, EJ: Methodology, Formal analysis, Data Curation. MK, CJK, KHS, PGC, WBP: Conceptualization, Methodology, Investigation, Writing Review \& Editing. KUP: Supervision, Methodology. ESK, NJK, MDO: Supervision, Writing - Review \& Editing. HBK: Funding acquisition, Supervision, Writing - Review \& Editing. All authors have read and approved the final manuscript.

\section{Funding}

This study was supported by a research grant (13-2014-002) from Seoul National University Bundang Hospital (Seongnam, South Korea). The funder had no role in the design of the study and collection, analysis, and interpretation of data and in writing the manuscript.

\section{Availability of data and materials}

The datasets generated and analysed during the current study are available from the corresponding author on reasonable request.

\section{Ethics approval and consent to participate}

This study was approved by the Committee of Institutional Ethics Review Board (IRB) at Seoul National University Hospital (1403-024-562) and Seoul National University Bundang Hospital (B-1402-237-002). All participants, including healthy volunteers, provided written informed consent unless the requirement for waiver of informed consent was met. An informed consent 
was waived by the two IRBs for SAB patients who died or were discharged before D14 of SAB.

\section{Consent for publication}

Not applicable.

\section{Competing interests}

The authors declare no competing financial interests or personal relationships that could have influenced the work reported in this paper.

\section{Author details}

'Department of Internal Medicine, Seoul National University Hospital, Seoul National University College of Medicine, Seoul, Republic of Korea. ${ }^{2}$ Department of Internal Medicine, Seoul National University Bundang Hospital, Seoul National University College of Medicine, 173 Gumi-ro, Bundang-gu, Seongnam 463-707, Republic of Korea. ${ }^{3}$ Department of Laboratory Medicine, Seoul National University Bundang Hospital, Seou National University College of Medicine, Seongnam, Republic of Korea. ${ }^{4}$ Present Address: Roche Korea, Seoul, Republic of Korea. ${ }^{5}$ Medical Research Collaborating Center, Seoul National University Bundang Hospital, Seongnam, Republic of Korea. ${ }^{6}$ Present Address: Department of Internal Medicine, Ewha Womans University, Seoul Hospital, Seoul, Republic of Korea.

\section{Received: 6 July 2020 Accepted: 19 November 2020}

\section{Published online: 30 November 2020}

\section{References}

1. Lowy FD. Staphylococcus aureus infections. N Engl J Med. 1998;339(8): 520-32.

2. Liu C, Bayer A, Cosgrove SE, Daum RS, Fridkin SK, Gorwitz RJ, Kaplan SL, Karchmer AW, Levine DP, Murray BE, et al. Clinical practice guidelines by the infectious diseases society of america for the treatment of methicillinresistant Staphylococcus aureus infections in adults and children. Clin Infect Dis. 2011;52(3):e18-55

3. Kang Cl, Song JH, Ko KS, Chung DR, Peck KR. Asian network for surveillance of resistant pathogens study $\mathrm{G}$ : clinical features and outcome of Staphylococcus aureus infection in elderly versus younger adult patients. Int J Infect Dis. 2011;15(1):e58-62.

4. Tacconelli E, Pop-Vicas AE, D'Agata EM. Increased mortality among elderly patients with meticillin-resistant Staphylococcus aureus bacteraemia. J Hosp Infect. 2006;64(3):251-6.

5. Lesens $O$, Methlin C, Hansmann $Y$, Remy V, Martinot M, Bergin C, Meyer P, Christmann D. Role of comorbidity in mortality related to Staphylococcus aureus bacteremia: a prospective study using the Charlson weighted index of comorbidity. Infect Control Hosp Epidemiol. 2003:24(12):890-6.

6. Turnidge JD, Kotsanas D, Munckhof W, Roberts S, Bennett CM, Nimmo GR, Coombs GW, Murray RJ, Howden B, Johnson PD, et al. Staphylococcus aureus bacteraemia: a major cause of mortality in Australia and New Zealand. Med J Aust. 2009:191(7):368-73.

7. Hill PC, Birch M, Chambers S, Drinkovic D, Ellis-Pegler RB, Everts R, Murdoch D, Pottumarthy S, Roberts SA, Swager C, et al. Prospective study of 424 cases of Staphylococcus aureus bacteraemia: determination of factors affecting incidence and mortality. Intern Med J. 2001;31(2):97-103.

8. Kaech C, Elzi L, Sendi P, Frei R, Laifer G, Bassetti S, Fluckiger U. Course and outcome of Staphylococcus aureus bacteraemia: a retrospective analysis of 308 episodes in a Swiss tertiary-care Centre. Clin Microbiol Infect. 2006;12(4):345-52.

9. Cosgrove SE, Sakoulas G, Perencevich EN, Schwaber MJ, Karchmer AW, Carmeli Y. Comparison of mortality associated with methicillin-resistant and methicillin-susceptible Staphylococcus aureus bacteremia: a meta-analysis. Clin Infect Dis. 2003;36(1):53-9.

10. van Hal SJ, Jensen SO, Vaska VL, Espedido BA, Paterson DL, Gosbell IB. Predictors of mortality in Staphylococcus aureus bacteremia. Clin Microbiol Rev. 2012;25(2):362-86.

11. Chong YP, Kim ES, Park SJ, Park KH, Kim T, Kim MN, Kim SH, Lee SO, Choi $\mathrm{SH}$, Woo JH, et al. Accessory gene regulator (agr) dysfunction in Staphylococcus aureus bloodstream isolates from south Korean patients. Antimicrob Agents Chemother. 2013;57(3):1509-12.

12. McNicholas S, Talento AF, O'Gorman J, Hannan MM, Lynch M, Greene CM, Humphreys H, Fitzgerald-Hughes D. Cytokine responses to Staphylococcus aureus bloodstream infection differ between patient cohorts that have different clinical courses of infection. BMC Infect Dis. 2014;14:580.

13. Rose WE, Eickhoff JC, Shukla SK, Pantrangi M, Rooijakkers S, Cosgrove SE, Nizet V, Sakoulas G. Elevated serum interleukin-10 at time of hospital admission is predictive of mortality in patients with Staphylococcus aureus bacteremia. J Infect Dis. 2012;206(10):1604-11.

14. Fournier B, Philpott DJ. Recognition of Staphylococcus aureus by the innate immune system. Clin Microbiol Rev. 2005;18(3):521-40.

15. Yimin KM, Zhao S, Ozaki M, Haga S, Nan G, Kuge Y, Tamaki N. Contribution of toll-like receptor 2 to the innate response against Staphylococcus aureus infection in mice. PLoS One. 2013;8(9):e74287.

16. Gillrie MR, Zbytnuik L, McAvoy E, Kapadia R, Lee K, Waterhouse CC, Davis SP, Muruve DA, Kubes P, Ho M. Divergent roles of toll-like receptor 2 in response to lipoteichoic acid and Staphylococcus aureus in vivo. Eur J Immunol. 2010:40(6):1639-50.

17. Fournier B. The function of TLR2 during staphylococcal diseases. Front Cell Infect Microbiol. 2012;2:167.

18. Akira S, Takeda K. Toll-like receptor signalling. Nat Rev Immunol. 2004;4(7): 499-511.

19. Kumar H, Kawai T, Akira S. Pathogen recognition in the innate immune response. Biochem J. 2009:420(1):1-16.

20. Bardoel BW, Vos R, Bouman T, Aerts PC, Bestebroer J, Huizinga EG, Brondijk $\mathrm{TH}$, van Strijp JA, de Haas CJ. Evasion of toll-like receptor 2 activation by staphylococcal superantigen-like protein 3. J Mol Med (Berl). 2012;90(10): 1109-20.

21. Koymans KJ, Goldmann O, Karlsson CAQ, Sital W, Thanert R, Bisschop A, Vrieling M, Malmstrom J, van Kessel KPM, de Haas CJC, et al. The TLR2 antagonist staphylococcal Superantigen-like protein 3 acts as a virulence factor to promote bacterial pathogenicity in vivo. J Innate Immun. 2017;9(6): 561-73.

22. Askarian F, Wagner T, Johannessen M, Nizet V. Staphylococcus aureus modulation of innate immune responses through toll-like (TLR), (NOD)like (NLR) and C-type lectin (CLR) receptors. FEMS Microbiol Rev. 2018; 42(5):656-71.

23. Miller LS, Fowler VG, Shukla SK, Rose WE, Proctor RA. Development of a vaccine against Staphylococcus aureus invasive infections: evidence based on human immunity, genetics and bacterial evasion mechanisms. FEMS Microbiol Rev. 2020:44(1):123-53.

24. Mele T, Madrenas J. TLR2 signalling: at the crossroads of commensalism, invasive infections and toxic shock syndrome by Staphylococcus aureus. Int J Biochem Cell Biol. 2010;42(7):1066-71.

25. Schaaf B, Luitjens K, Goldmann T, van Bremen T, Sayk F, Dodt C, Dalhoff K, Droemann D. Mortality in human sepsis is associated with downregulation of toll-like receptor 2 and CD14 expression on blood monocytes. Diagn Pathol. 2009:4:12.

26. Salomao R, Martins PS, Brunialti MK, Fernandes Mda L, Martos LS, Mendes ME, Gomes NE, Rigato O. TLR signaling pathway in patients with sepsis. Shock. 2008;30(Suppl 1):73-7.

27. Armstrong L, Medford AR, Hunter KJ, Uppington KM, Millar AB. Differential expression of toll-like receptor (TLR)-2 and TLR-4 on monocytes in human sepsis. Clin Exp Immunol. 2004;136(2):312-9.

28. Moore CE, Segal S, Berendt AR, Hill AV, Day NP. Lack of association between toll-like receptor 2 polymorphisms and susceptibility to severe disease caused by Staphylococcus aureus. Clin Diagn Lab Immunol. 2004:11(6):1194-7.

29. Charlson ME, Pompei $P$, Ales KL, Mackenzie CR. A new method of classifying prognostic comorbidity in longitudinal studies: development and validation. J Chronic Dis. 1987:40(5):373-83.

30. Paterson DL, Ko WC, Von Gottberg A, Mohapatra S, Casellas JM, Goossens H, Mulazimoglu L, Trenholme G, Klugman KP, Bonomo RA, et al. International prospective study of Klebsiella pneumoniae bacteremia: implications of extended-spectrum beta-lactamase production in nosocomial infections. Ann Intern Med. 2004;140(1):26-32.

31. Vincent JL, Moreno R, Takala J, Willatts S, De Mendonca A, Bruining H, Reinhart CK, Suter PM, Thijs LG. The SOFA (Sepsis-related organ failure assessment) score to describe organ dysfunction/failure. On behalf of the working group on Sepsis-related problems of the European Society of Intensive Care Medicine. Intensive Care Med. 1996:22(7):707-10.

32. Friedman ND, Kaye KS, Stout JE, McGarry SA, Trivette SL, Briggs JP, Lamm W, Clark C, MacFarquhar J, Walton AL, et al. Health care-associated bloodstream infections in adults: a reason to change the 
accepted definition of community-acquired infections. Ann Intern Med. 2002;137(10):791-7.

33. Jang HC, Kim SH, Kim KH, Kim CJ, Lee S, Song KH, Jeon JH, Park WB, Kim $H B$, Park SW, et al. Salvage treatment for persistent methicillin-resistant Staphylococcus aureus bacteremia: efficacy of linezolid with or without carbapenem. Clin Infect Dis. 2009;49(3):395-401.

34. Rose WE, Shukla SK, Berti AD, Hayney MS, Henriquez KM, Ranzoni A, Cooper MA, Proctor RA, Nizet V, Sakoulas G. Increased endovascular Staphylococcus aureus inoculum is the link between elevated serum interleukin 10 concentrations and mortality in patients with bacteremia. Clin Infect Dis. 2017:64(10):1406-12.

35. Kullar R, McKinnell JA, Sakoulas G. Avoiding the perfect storm: the biologic and clinical case for reevaluating the 7-day expectation for methicillinresistant Staphylococcus aureus bacteremia before switching therapy. Clin Infect Dis. 2014:59(10):1455-61.

36. Schmittgen TD, Livak KJ. Analyzing real-time PCR data by the comparative C(T) method. Nat Protoc. 2008;3(6):1101-8.

37. Bustin SA, Benes V, Garson JA, Hellemans J, Huggett J, Kubista M, Mueller R, Nolan T, Pfaffl MW, Shipley GL, et al. The MIQE guidelines: minimum information for publication of quantitative real-time PCR experiments. Clin Chem. 2009;55(4):611-22.

38. Minejima E, Bensman J, She RC, Mack WJ, Tuan Tran M, Ny P, Lou M, Yamaki J, Nieberg P, Ho J, et al. A Dysregulated balance of Proinflammatory and anti-inflammatory host cytokine response early during therapy predicts persistence and mortality in Staphylococcus aureus bacteremia. Crit Care Med. 2016:44(4):671-9.

39. Hoebe K, Georgel P, Rutschmann S, Du X, Mudd S, Crozat K, Sovath S, Shamel L, Hartung T, Zahringer U, et al. CD36 is a sensor of diacylglycerides. Nature. 2005:433(7025):523-7.

40. Hilmi D, Parcina M, Stollewerk D, Ostrop J, Josten M, Meilaender A, Zaehringer U, Wichelhaus TA, Bierbaum G, Heeg K, et al. Heterogeneity of host TLR2 stimulation by Staphylocoocus aureus isolates. PLoS One. 2014; 9(5):e96416.

41. Hanzelmann D, Joo HS, Franz-Wachtel M, Hertlein T, Stevanovic S, Macek B, Wolz C, Gotz F, Otto M, Kretschmer D, et al. Toll-like receptor 2 activation depends on lipopeptide shedding by bacterial surfactants. Nat Commun. 2016;7:12304.

42. Testro AG, Gow PJ, Angus PW, Wongseelashote S, Skinner N, Markovska V, Visvanathan $\mathrm{K}$. Effects of antibiotics on expression and function of toll-like receptors 2 and 4 on mononuclear cells in patients with advanced cirrhosis. J Hepatol. 2010;52(2):199-205.

43. Moore LJ, Pridmore AC, Dower SK, Read RC. The glycopeptide vancomycin does not enhance toll-like receptor 2 (TLR2) activation by Streptococcus pneumoniae. J Antimicrob Chemother. 2004;54(1):76-8.

44. Bode C, Diedrich B, Muenster S, Hentschel V, Weisheit C, Rommelsheim K, Hoeft A, Meyer R, Boehm O, Knuefermann P, et al. Antibiotics regulate the immune response in both presence and absence of lipopolysaccharide through modulation of toll-like receptors, cytokine production and phagocytosis in vitro. Int Immunopharmacol. 2014;18(1):27-34.

45. Jekarl DW, Lee SY, Lee J, Park YJ, Kim Y, Park JH, Wee JH, Choi SP. Procalcitonin as a diagnostic marker and IL-6 as a prognostic marker for sepsis. Diagn Microbiol Infect Dis. 2013;75(4):342-7.

46. Gogos CA, Drosou E, Bassaris HP, Skoutelis A. Pro- versus anti-inflammatory cytokine profile in patients with severe sepsis: a marker for prognosis and future therapeutic options. J Infect Dis. 2000;181(1):176-80.

47. Song KH, Kim ES, Sin HY, Park KH, Jung SI, Yoon N, Kim DM, Lee CS, Jang HC, Park Y, et al. Characteristics of invasive Staphylococcus aureus infections in three regions of Korea, 2009-2011: a multi-center cohort study. BMC Infect Dis. 2013;13:581.

\section{Publisher's Note}

Springer Nature remains neutral with regard to jurisdictional claims in published maps and institutional affiliations.

Ready to submit your research? Choose BMC and benefit from:

- fast, convenient online submission

- thorough peer review by experienced researchers in your field

- rapid publication on acceptance

- support for research data, including large and complex data types

- gold Open Access which fosters wider collaboration and increased citations

- maximum visibility for your research: over $100 \mathrm{M}$ website views per year

At $\mathrm{BMC}$, research is always in progress.

Learn more biomedcentral.com/submissions 